(This is an extended version of a chapter that first appeared in Gerry Bloustein et al eds. Sonic Synergies: Music, Technology, Community, Identity (Ashgate, 2008))

\title{
The Idol Audience: Judging, Interactivity and Entertainment
}

'You're an ordinary boy and That's the way I like it'

'Dirty Jeans' by Magic Dirt

This article is about Australian Idol, the Australian version of the talent quest for singers made to the format of the British show, Pop Idol, which first aired in 2001. The Idol format has proved to be incredibly popular with viewers and has now been picked up in over thirty countries from the United States to Kazakhstan and Malaysia. Central to the format is its competitive edge, pitting singers against one another until only one is left. It is this one who becomes the Australian Idol.

Crucial to the structure of the format is the way decisions are made about which contestants should go forward. The format calls for a panel of three judges who begin by choosing 118 (in the case of Australian Idol 2) contestants from those across Australia who auditioned. These were limited in age to between eighteen and twenty-eight. Once the judges had brought down this number to thirty, the novel part of the talent quest format kicked in. The judges' role was reduced to commenting on the contestants' performances and the viewers were able to vote, most usually by means of the mobile phone text messaging service (Short Messaging Service known as SMS) for the singer they preferred. In this way the contestants were eliminated until only the winner remained. Not original to the Idol format, this process of viewer participation has become generally identified as the leading edge of television interactivity. In this article I want to think through some of the elements of this interactivity, most specifically as these can be elucidated through tensions between the show's judges and the choices of the voting viewer audience.

\section{Popular Idol}

The Idol format owes much to the slightly earlier 'reality pop' show, to use Su Holmes term, ${ }^{1}$ Popstars. Indeed, as Holmes writes: 'The reality pop programs began with the New Zealand (in 1999) and Australian Popstars (in 2000). ${ }^{2}$ So similar were Popstars and Pop Idol considered to be that the Format Recognition and Protection Association 
based in Cologne, Germany, the industry body 'formed in April 2000, that mediates disputes between producers of similar formats, ${ }^{3}$ decided that the Pop Idol format could not use the word 'Pop' in its name outside of the United Kingdom. Hence, we have the rather nationalistic sounding Australian Idol, American Idol and so forth.

Popstars was the brainchild of New Zealand producer, John Dowling. The idea of the show was to follow the construction of a girl group by the use of a panel of three judges. Dowling had a history in documentary making so it is no wonder that the format of Popstars has the feel of a behind-the-scenes look at how a pop group is constructed at the turn of the twenty-first century. In the context of a discussion of 'ordinariness,' a discourse to which we must return, Misha Kavka writes that:

'It is interesting to note that Popstars begins with an entire episode (and in later versions more than one episode) devoted to the initial casting call. In this way, we get to see people 'like ourselves' coming in off the streets as it were, and singing for the producers. I suspect that it is this inclusion of the casting call in the format that made Popstars so globally marketable. ${ }^{4}$ Unpacking this, and following Kavka's idea, we can suggest that it is Popstars' documentary influence, the showing of average people, people with whom the viewing audience can identify as being similar to themselves, striving to become popular music celebrities which made the program so attractive to audiences.

Popstars did not have a viewer voting system. The Popstars format was organised as a generic combination of documentary and talent quest or, to put it differently, Popstars revealed as a televisual entertainment the managerial process of deliberately putting together a group with the intention of making a hit record, what, in a slightly different context, has been called the "star-making machinery." ${ }^{5}$ Dowling sold the concept of Popstars to the Australian production company Screentime which developed the format and has sold it to over twenty countries including the United States, India, the United Kingdom, Argentina and much of Europe.

Popstars, then, was the very successful precursor to the Idol phenomenon. From the show's point of view this success has been as a televisual entertainment. However, as the creators of Idol were to understand very well, the popularity of this entertainment also functioned as the most remarkable advertising tool for the product, in the first instance a single and an album, released by the completed group. Thus, for example, the New 
Zealand Popstars group, trueBliss, managed by Dowling himself, had a number one single with 'Tonight' and their album, Dream, also went straight to number one on the New Zealand album chart in 1999 and went platinum. Bardot, the first Australian Popstars group, had both their first single 'Poison', and their first self-titled album, debut at the top of the charts. It is no wonder that the most important aspect of the prize in Idol is a recording contract with the company that also supplies one of the judges, BMG.

If Popstars provided one conceptual foundation for Idol, another was the talent quest, of which the most important examples in Britain were Opportunity Knocks (19561978) and New Faces (1973-1978). Both these shows had elements reworked in the Idol format. In New Faces, acts were evaluated by a panel of four 'expert' judges. As in Idol, comments were often direct and cutting. In Opportunity Knocks contestants were evaluated by the studio audience and given a rating according to the clapometer. However, viewers sent in postcards with their choice and it was the act that got the most mailed-in votes which won. ${ }^{6}$ In other words, as we shall see, the studio audience in Opportunity Knocks had a similar role as in Idol, providing a guide for the home television-viewing audience. We could suggest that this difference led to a difference in what was being looked for-the judges in New Faces wanting to find 'quality' while the audience in Opportunity Knocks being more interested in being entertained and voting for what they liked. In Idol, the viewer voting mechanism has been immensely speeded up. Idol's viewer voting method, though, was modelled on that used in the Dutch-originated reality television format, Big Brother. In this show a number of contestants, usually around fourteen, are chosen to live together for a number of weeks, around twelve, isolated from the outside world with hidden cameras everywhere in the house. The material recorded by the cameras is then edited for television. In Australia 'typically, the Big Brother week consisted of eight shows: five half-hour episodes and three hour-long episodes, an average of five and a half hours of programming per week. ${ }^{7}$ In addition, there was a live feed to the Australian Big Brother internet site. Every week the contestants would each separately nominate two of their housemates for eviction, with more points going to the one they would rather have evicted. Viewers were then asked to vote for which of the most-nominated evictees they would like to see expelled from the house. The last person in the house was the winner. The winner received a large cash prize. 
This format was inspired by the American MTV program, The Real World, broadcast first in 1992. As described by Misha Kavka and Amy West, The Real World 'brings together a group of strangers in an isolated environment to cohabit for a predetermined period of time, during which they must complete certain challenges and vote individuals out of the game.' 8 John de Mol, a Dutchman, began devising Big Brother in 1994 when his production company merged with that of Joop van den Ende to form Endemol. By the time the first Big Brother went to air in the Netherlands in September 1999, Endemol had worked out the mechanics of a new viewer voting system and also the process of selling access to the format-something pioneered by the British show, Who Wants To Be A Millionaire? which first aired in 1998.

There have now been versions of the Big Brother format screened in over twenty countries, Australia's first Big Brother aired in 2001. A very few statistics gleaned from Toni Johnson-Woods' book offer a sense of the general popularity of the show. In the Netherlands, the final of the first series, on New Year's Eve 1999, was watched by over 50 per cent of the Dutch population. ${ }^{9}$ In Argentina, the final episode had a 90 per cent viewer share. ${ }^{10}$ In Britain, ten million people watched the final episode of the first series. $^{11}$

Interactivity has not been the key to the success of Big Brother but it has been an important contributing element. In the United Kingdom, for example, 7,255,094 votes were cast in the final round. ${ }^{12}$ However, according to Chris Short, Endemol UK's Head of Interactive: 'The reason that Big Brother has been such a success .... isn't because of all the interactive applications, but because it's compelling TV that lends itself to interactivity. ${ }^{13}$ Indeed, as we have already seen, interactivity in the sense of viewer voting is nothing new, it is simply less cumbersome now than in the days when viewers sent in postcards to Opportunity Knocks. Big Brother can, and has, run without viewers voting. In the first American Big Brother contestants voted each other out, much as they do in the American Survivor reality format. ${ }^{14}$ The point here is that viewer voting is not integral to the format of Big Brother and, indeed, it is not integral to the Idol format. However, the shift from Popstars using judges to Idol using viewer voting and from The Real World and Survivor where contestants vote each other out to Big Brother viewer voting marks a key shift in the cultural acceptance of a form of televisual interaction. Paul Sloan tells us that: 
'Fans cast more than 65 million votes for the American Idol finale in May [2004], that's two-thirds as many people as voted in the 2000 U.S. presidential election. In the Czech Republic, more than a third of the nation's 10 million people voted on the Cseko Hleda SuperStar finale. A blizzard of phoned-in votes for Finland's Idol finale crippled part of the country's telecom system., 15

Sloan's misunderstanding here, and it is as we shall see quite an important one, is to assume that, as in a democratic election, each eligible person only votes once. In the viewer voting system as it currently exists this is not the case. Viewers can vote as many times as they like or, in some countries depending on the voting method used, as they can afford.

Making this possible has been the development and social acceptance of a variety of communication technologies. In Britain, for example, eighteen percent of the votes cast in the final round of Big Brother, 1,305,917, were delivered through iTV where viewers pressed a red button on a set-top digital television box. In the United States the majority of viewer votes in the first Idol series were cast by means of a free 1800 number. Jon Penn, FremantleMedia's Licensing Asia Pacific licensing officer is quoted as saying that:

"In Australia, we found that more than two thirds of the voting came from SMS. In New Zealand, the figure was $80 \%$. In the U.K., SMS use is lower - less than half." 16

Most of the rest of the calls were made using land-lines. From the point of view of the format licencee and the telecommunication companies, SMS is the preferred voting technology because they can set the cost of each call and then share the profit. To put this another way, the use of mobile phone SMS technology for voting is another revenue stream. For Australian Idol 1, not including the final, it was estimated that Idol voters spent \$Aus25 million on telephone calls and SMS. ${ }^{17}$ Indeed, it seems that: 'Australia is the world leader in "voting conversion rate," with half as many voters again as there were viewers for its final. ${ }^{18}$ The final of Idol 1 had 3.11 million viewers. It is no wonder that the format licencees and telecoms are not interested in securing any equalisation of voting, say one vote per phone, because, quite simply, the more a person votes, the greater the revenue. 
The Idol format was first roughed out by Simon Fuller and then developed by himself and Simon Cowell, working as a representative of BMG. Fuller started out as an A \& R person for Chrysalis. His first discovery was Paul Hardcastle in the mid-1980s. Fuller subsequently named his company after Hardcastle's number one single, the Vietnam War song, '19.' However, before Idol, Fuller was best known for his management of the 1990s girl group, the Spice Girls. Fuller didn't invent the Spice Girls, Bob and Chris Herbert had the original idea of promoting an all-girl group who appealed equally to boys and girls. They 'had selected the five originals after an extensive mass audition process, [and] subjected the five to an intensive course of singing and dancing. ${ }^{19}$ Subsequently the Girls replaced the Herberts with Fuller.

Already it should be clear that both Popstars and Idol work over the same ground as the process which produced the Spice Girls. In particular, Fuller reinvented his and the Herberts' own past as a spectacle and entertainment. The Spice Girls sacked Fuller after eighteen months. However, by then the group had a marketed image and their first single, 'Wannabe', had stayed at number one in the British charts for seven weeks. ${ }^{20}$ By the end of 1996 'Wannabe' had topped the charts in a further twenty-one countries. Their second single, 'Say You'll Be There,' also went straight to number one in Britain. Their first album, Spice, went to number one on its release at the end of the same year, 1996.

Central to their assertion of 'girl power' was the group's claim to be just the same as their audience of teenage girls. Sheila Whiteley quotes from Kathy Acker's interview with the group published in the Weekend Guardian in 1997: 'What I think is fan-fuckingtastic about us is that we are not perfect and we have made a big success of ourselves.... We were all individually beaten down... Collectively we've got something going. Individually, I don't think we'd be that great.' ${ }^{21}$ Here we should be reminded most obviously of Kavka's insight about showing the auditions in Popstars-the Girls' point here is precisely that their ordinariness is the source of their success.

In Idol, where we also see the auditions, as the numbers are whittled down so we get increasing amounts of footage of the contestants' day-to-day lives, their families, and anything else which will balance off the contestants' growing celebrity status with a claim to their underlying mundanity. In Idol, Fuller repeated in part the insight that made the Spice Girls so successful: that pre-teen and teenage girls look for a 'star' with whom they can identify. 
One of Idol's strengths lies in its narrative structure. As Alan Boyd, FremantleMedia's President for Worldwide Entertainment, and the man to whom Fuller and Cowell pitched their idea, puts it: 'The dream was to create a talent show that played out like a drama over a series of weeks with the excitement of a presidential election. ${ }^{22}$ Idol has a strong narrative line which builds steadily towards a dramatic climax with a set of soap opera-style cliff-hangers along the way. As it happens, the recognition that this is the way to hold and build a viewing audience has become well-known, perhaps as a consequence of sports competition broadcasts.

Figures for the largest Australian television audiences between 2001 and 2003, that is excluding Australian Idol 2, show that the Idol 1 final came in between the Rugby World Cup Final, which had the largest audience at 4.01 million and the auction of the flats renovated in the reality television competition, The Block, at 3.11 Million. All three finals came ahead of the viewing figures for the 2001 terrorist attacks on the World Trade Center and the Pentagon which had a combined viewing figure across three television stations of 3.10 million. Beneath this were two more sports finals, Wimbleton day 14, 2001 (when Goren Ivanisevic beat Australia’s Pat Rafter in the men’s singles' final) at 3.16 million and the AFL grand final 2003 at 2.96 million. Below this is the final of the 2004 series of Big Brother coming in at 2.86 million. The list goes on in the same vein. The final of Australian Idol 2 had a viewing figure of 3.55 million, significantly more than that of the first Australian Idol final. All these shows have the same basic climactic structure building over a number of weeks of cliffhanger eliminations.

\section{Idol Theory}

How can we think about these shows in which the outcome is 'real' in the sense that it is unknown until it happens, unlike for example a drama, and yet which is constructed and organised precisely like a drama. Of course, such programming is not, in itself, new, quiz shows, for example, have been structured in this way for a long time. However, shows such as the Rugby World Cup and Australian Idol have generated a very significant development in the form. One way of beginning to theorise these shows is by means of Daniel Boorstin's idea of the pseudo-event. Boorstin's book, The Image, was published in 1961 when television was still, relatively speaking, in its infancy. Boorstin writes of a pseudo-event that: 
1. It is not spontaneous, but comes about because someone has planned, planted or incited it. Typically it is not a train wreck or an earthquake, but an interview.

2. It is planted primarily (not always exclusively for the immediate purpose of being reported or reproduced...)

3. Its relation to the underlying reality of the situation is ambiguous. Its interest arises largely from this very ambiguity. ${ }^{23}$

The idea is to get the pseudo-event included on the News. As a show which lays claim to telling us something about the 'real world,' the world in which we live, Idol has just the ambiguity Boorstin describes. Idol, though, is not constructed as a News item-and, of course, the construction of News has shifted a great deal from the time of The Image. News now has moved more towards infotainment.

While Idol is produced as an entertaining competition for television viewers, it is 'real' enough as a show dedicated to finding who Australians want as their idol—and the ambiguities around this idea will be discussed below - that, as the show reaches its final stages, so it bleeds into News programming on television, but also in the other mass media. Thus, for example, in an article by Suzanne Carbone in The Age, 19/11/2003, titled 'Your last chance to create an idol,' the very fact that the Australian Idol final was approaching and that people could vote for either of the two remaining contestants was considered newsworthy. In The Australian, 22/11/2004, Sophie Tedmanson's article, 'One of the girls: Casey Idolised,' that Casey Donovan had won Australian Idol 2 was thought to be newsworthy.

When Guy Debord, in his 1967 book, Le société du spectacle, discussed his idea of the increasing spectacularisation of society, he was not thinking of individual programs but the overall effects produced by the mass media. He wrote that:

'If the spectacle- understood in the limited sense of those "mass media" that are its most stultifying superficial manifestation—seems at times to be invading society in the shape of a mere apparatus, it should be remembered that this apparatus has nothing neutral about it, and that it answers precisely to the needs of the spectacle’s internal dynamics. ${ }^{24}$

Debond's Marxian concern here is with the underlying capitalist dynamic of the spectacularisation process. The increased sophistication of voting interactivity can be 
thought of as producing a greater degree of incorporation of the audience into this spectacle.

One theme which I have been developing is that Idol, Big Brother and other competitive reality television shows are functionally similar to the large sporting shows and in their tactics for acquiring and holding on to audiences are a step forward in the process of spectacularisation. This development is amplified in the case of Big Brother and Idol where interactivity in the form of the viewer voting, and also the range of chatrooms and blog sites on the web to which viewers can contribute, appears to offer viewers power while further incorporating them into the spectacle. Thus, Holmes explains that in Britain: 'Explicitly distinguishing itself from Popstars in its invocation of audience interactivity, democracy, and popular taste, Pop Idol's promotional rhetoric insisted, "But this time, you choose!", ${ }^{25}$ While in the democratic political process whom a person can vote for, and the usefulness of that vote, is determined by the electoral system in use (for example, first past the post or proportional representation), in Idol, whom the viewers can vote for has already been limited by the show's own judges. When Debord writes that: 'The spectacle is not a collection of images; rather it is a social relationship between people that is mediated by images, ${ }^{26}$ viewer voting heightens this mediation by further incorporating the viewers into the spectacle.

Writers about reality television frequently invoke the category of 'ordinary people'. Holmes, for example, in her discussion of celebrity in Big Brother, writes that:

'It is not, of course, new for ordinary people to appear on television. Genres as diverse as news, quiz shows and documentaries have long since relied upon the role and presence of 'real' people as opposed to media professionals and performers. ${ }^{27}$

Holmes' invocation of the News and quiz shows should serve to remind us of Boorstin's definition of a pseudo-event. What gives the pseudo-event its ambiguity, what serves to tie a pseudo-event to the 'real,' is the presence of ordinary people.

Holmes rightly problematizes the 'real.' The 'real' in this context is the everyday life that is identified as existing outside of the constructed frame of the program, the housemates' house in Big Brother, the Idol performances and all that is associated with those in the Idol series. The 'real' then, is a dichotomous construction. However, the use of 'ordinary people,' especially in British academic work, is still to an extent over- 
determined by its history. In 1958 Raymond Williams published a foundational, and still important, essay called 'Culture is Ordinary.' In this piece Williams asserts the relevance of understanding culture as produced in and through lived experiences. He goes on to explain that:

'Culture is ordinary: That is the first fact. Every human society has its own shape, its own purposes, its own meanings'

and later writes, using a phrase which was to become synonymous with his name, that: 'We use the word culture in these two senses to mean a whole way of life-the common meanings; to mean the arts and learning - the special processes of discovery and creative effort. $^{, 28}$ As a theoretical term, the idea of ordinary people carries the baggage of Williams’ battle to have ordinary culture taken seriously.

As it happens, Williams' concern with the ordinary was part of a broader shift in late 1950s English culture which included the advent of the so-called 'kitchen sink' fictions such as John Brain’s 1957 novel, Room at the Top (released as a film in 1959) and Shelagh Delaney's 1957 novel, A Taste of Honey, (released as a film in 1961). Ted Willis, whose television play about a working class man whose wife cannot keep house and his affair with a work colleague, Woman in a Dressing Gown, was broadcast in 1956 (and released as a film in 1957) and who created the character of George Dixon, the neighbourhood policeman who appeared in the long-running television series Dixon of Dock Green (1955-1976), remarked of Brain's and Delaney’s work that: ‘They [both] deal with the mundane, the ordinary and the untheatrical. The main characters are typical rather than exceptional ... I am just becoming aware of this area, this marvellous world of the ordinary. ${ }^{29}$ Richard Hoggart's foundational The Uses of Literacy subtitled 'Aspects of Working Class Life' was published in 1957. The introduction of the ordinary, then, has a lot to do with the English artistic and intellectual recognition of working-class lifewhich, in turn, had a lot to do with the incursion of the working class into these worlds as a consequence of changes in secondary education brought about by the 1944 Education Act.

We need to remember that while in everyday use the notion of ordinary people carries with it a connection to a hermeneutic of the 'real'-as Estelle Tincknell and Parvati Raghuram write 'the increased visibility of 'ordinary people' on television is underlain by powerful commonsense assumptions about what constitutes the 'real world' 
in which 'real' is defined phenomenologically, ${ }^{30}$-that, in relation to the postdocumentary world of reality television, the idea of ordinary people needs to be understood as itself a dichotomous formation driven by the construction of the televisual world as somehow 'non-real.' Thus, as Tincknell and Raghuram note:

'Reality TV claims to feature 'ordinary’ people doing 'ordinary' things.

As a genre the 'people show' minimises the distance between the audience and the 'actors' through its emphasis on everyday life. ${ }^{31}$

Everyday life is itself a complex and much theorised idea. Michel de Certeau, for example, has defined it as, 'what we are given every day (or what is willed to us), what presses us, because there does exist an oppression of the present. ${ }^{32}$ However, structurally, as I have already remarked, everyday life is constructed as the world outside of the televisual experience of Idol, the world of the ordinary and of ordinary people. As Kavka suggests:

'In the rhetoric of many reality TV programmes, the participants are ordinary people, meaning only that they have never previously appeared before a television camera.' 33

The world of Idol is entered by way of the auditions; the judges are the gatekeepers to this special, televisual world. This ritual of entry to Idol-world, which minimises the ritual of exit other than in the tension surrounding the announcement, is as important a liminal moment as the eviction drama in Big Brother which maximises the importance of eviction but has little in the way of ritualised entry to the Big Brother house-world. Both rituals, though, serve to emphasise the dichotomy between the televisual and the non-televisual, 'real' worlds. In this the rituals help to balance the narrative insistence in both shows that the contestants are ordinary.

\section{Idol Interactivity}

In their article on the role of interactivity in Big Brother, Tincknell and Raghuram argue that, with the new possibilities of audience intervention, it becomes clear that the idea of the active audience as it was elaborated by such media theorists as David Morley and Ien Ang in the 1980s and 1990s was somewhat naïve in its assertion that audiences could be resistant to dominant meanings. Tincknell and Raghuram put their case like this: 'the idea of the active audience remained predicated on the assumption that activity constitutes an intellectual engagement with a text, rather than an intervention on a text, 
involving the refusal of dominant meanings and the production of new and oppositional meanings. ${ }^{34}$ They appear to equate the action of voting with the agency of engaging with a text and the meaning-load it bears, and generating alternative and sometimes resistant or oppositional meanings. For the active audience theorists, with their work located in semiotics and theories of culturally-based meaning making-here we can remember the long-term resonances of Williams' argument that culture is ordinary-it was the making sense of a text that was active, not necessarily the status of the meaning produced.

It is important to acknowledge this because as far back as 1996 in her book Living Room Wars, Ang moved this argument on. Ang argued that, 'the 'active audience' ... can be taken as a condensed image of the disorder of things in a postmodernized world-a world which has seriously destabilised the functionalist connection between television and modernity. ${ }^{35}$ She goes on to write that:

“'Choice' is now promoted as one of the main appeals of television to its audiences and is presented as the ultimate realisation of audience freedom. The proliferation of new technologies - such as satellite TV, fibre-optic cable, interactive television and so on - and the ever greater range of specialized programming for specialized audiences is creating an image world which seems to suggest there is something 'for everyone’s taste.’, 36

'Seen in this way', Ang continues, 'the figure of the 'active audience' has nothing to do with 'resistance', but everything to do with incorporation: the imperative of choice interpellates the audience as 'active'!, 37 Ang's point here is that choice, we might say apparent choice because this choice is always limited to what one-the audience-is offered, is a key element in post-Fordist, disorganised capitalism—-the term Ang uses following Scott Lash and John Urry in their The End of Organized Capitalism. The audience experiences itself as active, voting evictees out on Big Brother, voting for their preferred singer on Idol, but, structurally speaking, their activity is only implicating them more thoroughly into the postmodernized, consumption-driven, capitalist order (into Debord's spectacle).

We now need to begin thinking about the Australian Idol's audience in more detail. Australian Idol was broadcast on Channel Ten, usually thought of as the station aiming for the younger and 'more up-to-date' audience. It also happens to be the station 
that broadcast Big Brother so one section of Idol's audience would already have had some experience of viewer voting. The show went out on Sundays and Mondays in the early evening, between $7.30 \mathrm{pm}$ and 8.30 , early enough to catch the pre-teens upwards and during what is usually regarded as the family viewing time. Channel Ten's own breakdown of viewers shows that significantly more females than males watch the show: on Sunday evenings 59.1 percent to 40.9 percent and on Monday evenings 60.4 per cent to 39.6 per cent. Unfortunately, these figures are not broken down by age group. When we look at age grouping we find that the highest percentages of viewers are aged between 25 and 39, 31.8 per cent on Sunday evenings and 30.3 per cent on Monday evenings. The second largest viewing age group was that between 40 and 54, 22.2 per cent on Sundays and 22.0 percent on Mondays. In other words, on Sundays 54 per cent of viewers were aged between 25 and 54 and on Mondays this figure declined very slightly to 52.3 percent. With over half the viewers in this age group it is clear that the audience did not regard Australian Idol as purely a show for young people. Nevertheless, the show did attract a large youth audience: on Sundays 28.1 percent of the audience was aged 5 to 24 and on Mondays this figure grew in relation to the decline in the older viewing audience to 30.9 percent. $^{38}$

Now, we don't know if all age groups were watching the same program in the sense of bringing the same assumptions to their viewing. One surmise is that older viewers watched the show much as they would watch a variety show, for the entertainment value of the music and the performances. If this were so, it could further be summised that they would be more likely to identify and position themselves with the judges, who were also older, Marcia Hines was born in 1953, Mark Holden in 1954, and Ian "Dicko" Dickson in 1963, than with the studio audience which, aside from the relatives of the contestants, appeared to be comprised of early-to-mid-teens and to be predominantly female on a ration of somewhere between 2 and 3 to 1 . The younger television audience, then, would be more likely to identify with the studio audience, and with the contestants (remember the maximum age of the contestants was 28), and would, therefore, be more likely to involve themselves in the show as a competition.

What goes along with this supposition is that most likely the majority of viewers who voted each week came from the younger age group. Given that it is younger people who have picked up more quickly on the possibilities of SMS mobile phone technology and that, as we have seen, more than two thirds of the votes were cast using SMS, this 
would correlate with the supposition that, in the main, voters came from the younger age group.

Continuing on this theme, we have already seen how the construction of the Idol contestants as 'ordinary' enables a deeper identification by the audience. We have also seen this in operation with the girls who supported the Spice Girls. We can now think about the importance of the identificatory structure for young girls in Idol. Discussing the importance of the Spice Girls to younger girls, Whiteley quotes Angela McRobbie and Jenny Garber in 1975 that 'young pre-teen girls have access to less freedom than their brothers. Because they are deemed to be more at risk on the streets from attack, assault, or even abduction, parents tend to be more protective of their daughters. ${ }^{39}$ Whiteley adds that: 'The situation in the 1990s has, if anything, become more restrictive for the young girl as even the traditional 'freedom' to walk to and from school with friends has now been increasingly superseded by the child by the child being taken to and from school by an elder sibling and/or parent. ${ }^{40}$

In No Sense of Place, Joshua Meyrowitz makes use of an idea first elaborated by Donald Horton and Richard Wohl in an article called 'Mass Communication and ParaSocial Interaction,' published in 1956. In Meyrowitz' words Horton and Wohl argue that in a mass medium audience experience:

'although the relationship is mediated, it psychologically resembles face-to-face interaction. Viewers come to feel they "know" the people they "meet" on television in the same way they know their friends and associates. ${ }^{41}$

Meyrowitz further elaborates on Horton and Wohl's work:

'[They] note... that the para-social relationship has its greatest impact on the "socially isolated the socially inept, the aged and the invalid, the timid and rejected.” Because electronic media provide the types of interaction and experience which were once restricted to intimate live encounters, it makes sense that they would have their greatest effect on those who are physically or psychologically removed from everyday social interaction. $^{42}$

Here, then, we have a reinforcement of pre-teen and teen, especially female, identification with the Idol contestants. More, for a group as socially isolated and 
disempowered as these girls, voting must be experienced as a way of achieving agency; being able to exercise any choice is experienced positively.

\section{Idol Judges and Audiences}

Before we go on we need to say something about the structure of the critical system of Idol. As I have already indicated there is a panel of three judges, two male and one female. The judges have relevant specialisms which justify their comments and decisions on the contestants. Mark Holden was a pop music performer and has two double-gold albums to his credit who is now a successful songwriter and record producer. Marcia Hines is a consistently successful performer with many hit singles and albums during the second-half of the 1970s who now appeals to an audience aged roughly 40 and over. Her music could be described as soul-influenced, 'safe' and the middle-of-theroad, an adult version of the pop experience. Hines arrived in Australia in April 1970 to appear in the Sydney production of Hair. In addition to her expertise, Hines is also important to Australian Idol both as the only woman on the panel and also because she is African-American. From this speaking position Hines is able to head off complaints from singers perceived as non-white that the voting cohort is, on balance, prejudiced against them. At least once she has had to take on this role. The third judge for the first two Australian Idols has been "Dicko". Dickson worked in the music business for many years in the United Kingdom mostly packaging and marketing artists. Before coming to Australia he was Head of International at BMG. On Idol, Dicko represents BMG and, since the winner is guaranteed a recording contract with BMG, he judges in the interest of his employer, basically working in public as an A \& R person. Here is also a good place to point out that, as has happened in both Australian Idol 1 and 2, if Dicko thinks they can get the record sales, he will sign other contestants to BMG. In both Idols both the runners-up were signed, thus making a mockery of the competition but satisfying the contestants and BMG. ${ }^{43}$

The three judges each have a different persona. Holden is enthusiastic and slightly off-the-wall. Hines is caring and supportive, concentrating a lot on the contestants' vocal abilities and performances. Dicko is the straight-talking, critical businessman who knows that the bottom line is that a singer has to get their audience to buy records. This stereotypical male and female role division reinforces the sense of the judges as parental advisors. This ordering of the judges is laid down in the format for the show and Dicko's role is a version of the role played by Simon Cowell in the British and 
American Idols. The opinions of the judging panel are expected to be respected because of their expertise. The position of the panel is complicated, though, because while it is they who decide on the final thirty contestants, after that their role becomes simply to comment on the performers while the viewing audience votes for whom it prefers.

There are two audiences, the studio audience to whom the contestants perform live and the television viewing audience. I have already discussed the composition of these audiences. The structural role of the studio audience is to provide an identificatory way-in for the youthful television audience. The studio audience is expected to be uninhibited, waving banners for their favourite contestant and applauding with great gusto. In this behaviour they also become a part of the entertainment for the television audience-perhaps more for the older section of that audience who would not be likely to identify with the studio audience. The judging panel, which sits at the front of the audience, acts, as I have just suggested, as a version of the parental voice of reason. The expectation of the panel, who have just lost their decision-making power to the audience(s), is that the voters should heed their advice.

There are two possible basic voting systems that could be used: voters can vote for the person they prefer and so keep them in the competition, or they can vote for whom they dislike and so have them excluded from the competition. Big Brother uses the latter system. Voters vote for whom they want evicted from the house. Tincknell and Raghuram tell us that on the British Big Brother: 'Women who were produced (or produced themselves) as working class, 'stroppy,' sexually undesirable, or as heterosexually desiring in unconventional ways ... were voted out of the house as the weeks went by. ${ }^{44}$ In other words, by having to vote for the person they like the least, voters become much more aware that they can construct the cohort of contestants to be watched for the next week. One would suspect, also, that voting for whom you dislike is likely to produce less votes than voting for the person you like, this because the former requires a high amount of alienation from the person to pressure the audience into voting. In Idol, where the audience votes for the person they like in order to keep them in the competition, there is a greater sense of audience and contestant community-and, therefore, a greater audience and, one would expect, much greater voting.

Since voters can vote as many times as they like, or can afford, this raises the issue of voting constituencies. Just before the final of the first Australian Idol, the Sydney Morning Herald reported receiving an email 'explaining the finalists had been 
decided in advance, and that two relatives of contestants has logged 8000 votes between them. ${ }^{45}$ Setting aside the issue of the organisers rigging the competition, it could well be that some relatives of a contestant might feel that the financial, or other rewards of winning make the outlay of the cost of 8000 calls worthwhile. Similarly, other groupings may lobby for people to vote for a particular person. It is possible, for example, that, in a multicultural society, ethnic groups may mount campaigns for people to vote for the person from their background in the competition. Certainly during the finals voting for Australian Idol 2 many Indigenous chat-rooms and message-boards carried not only postings of support for the part-Indigenous Casey Donovan but also suggestions that as many Indigenous people as possible should vote for her as it would be good for the community if an Indigenous woman became the Australian Idol. One could imagine, equally, that in the final of Idol 1, the elders of Guy's church might have mobilised church members to vote for him. In a tight race such lobbying and multiple voting could have an effect.

\section{Idol Voting}

But what is it that the audience in Idol is voting for? Dicko is very clear what the purpose of the show is, and therefore what the panel is looking for. In his introduction to the DVD Australian Idol Uncut, which is a collection of the most excruciating auditions, he talks about 'the goal of Australian Idol':

'The objective of the competition is to find the very best undiscovered talent in Australia. As judges we assess each contestant in three categories: vocal ability, looks and star quality — that indefinable quality we constantly refer to as the $\mathrm{X}$-factor.'

While the older viewing audience might agree with this project, the way the program is constructed, the younger audience, and this probably includes the majority of voters, votes for the contestant they can identify with, a fantasy version of themselves making it in the big-time as a singer or, for some girls, a safe male fantasy object, one who is cuddly and not sexually threatening. The role of identification is one step on from the Opportunity Knocks' audience voting for what they like. It becomes more possible in Idol because of the bar on the age of the contestants and because of the increased immediacy of the voting process which enables voters to feel much more a part of the 
program and, therefore, closer to the contestants. Identification requires a much greater degree of affect.

In Australian Idol 2, the final twelve was comprised of five females and seven males. The final two were female and male, Casey Donovan and Anthony Callea. As well as being part-Indigenous, Casey is sixteen, overweight, had little dress sense, and, on screen, was constantly nervous and unsure of herself. As Sophie Tedmanson wrote in an article for The Australian: 'Donovan has been a role model to Idol viewerspredominantly teenage girls-including the thousands assembled on the Opera House forecourt to watch a live broadcast of the show and performances by other Idol contestants. $^{46}$ Anthony who was twenty-one, was short for a man, reputedly 167 centimetres, smiled frequently and, with his training at Johnny Young's Talent Time School behind him, appeared self-assured. Anthony comes from a Catholic Italian background. Guy Sebastian, who won the first Australian Idol, is a member of the Paradise Community Church which styles itself as 'contemporary Pentecostal.' Guy has publicly declared his virginity and his wish to remain a virgin until he gets married. In fact, from available information it would seem that the majority of the final twelves for both Idols have been committed Christians. Here, Christianity would seem to be experienced as connoting a subscription to normative Australian values.

I have mentioned that Casey is Indigenous and Anthony has an Italian background, Guy had a Ski Lankan heritage and was born in Klang in Malaysia. Paulini in the first Idol final twelve, and Angie in the second, both have Fijian backgroundsindeed, they are cousins. Many of the others in the final twelves came from non-AngloCeltic origins. Tincknell and Raghuram, writing about the British Big Brother, suggest that: 'The confines of the house enabled the programme to offer a space of 'safe multiculturalism,' because ethnic variations were presented not as racially conflicting but primarily as consensual. ${ }^{47}$ In Australia, Idol functioned in a similar way. Partly as a consequence of the genres from which the contestants had to pick songs, all sang songs in Western, primarily Anglo-American dominated, song forms. These genres included: the '70s, Australian Number Ones, R\&B/soul, and big band. There was no ethnic, or world music, genre week. There was one week, Personal Choice, when contestants could sing in any genre they wanted. By this time there were only eight contestants left. Only Anthony sang a song, 'The Prayer' by Italian tenor Andrea Boccelli and Celine Dion, partly in his heritage language, Italian. The ethnic and racial diversity of the contestants 
was made acceptable and safe by the Australo-normativity of their music, their clothes and their performances.

Guy, who won over the Italo-Australian Cosima De Vito who had to withdraw on medical advice to save her voice, and the Anglo-Celtic rock singer Shannon Noll who went into the final with Guy, smiled constantly. Ien Ang has discussed the ambivalent status of 'Asians' in Australian multiculturalism. Writing about a poem in which the speaker expresses her wish for a Vietnamese girl to leave Australia, to 'go home,' but is then charmed by the girl's smile, Ang asks, 'must Asianess be feminized in order to be welcomed into Australian culture?' and goes on: 'The Vietnamese girl's key to acceptance-her smile-is simultaneously the metaphoric seal of her approval and the sign of her continued positioning as other in an Australia that has learnt to be 'tolerant' and to enjoy and celebrate "cultural diversity. ${ }^{48}$ With his feminizing smile, his cuddly chubbiness, his Christianity and his virginity, Guy overcame any concerns that the voting audience might have had that he was not 'acceptably Australian'—which, of course, is not quite the same as being 'properly Australian' like Shannon with his echoes of Jimmy Barnes-like Oz Rock. ${ }^{49}$ In the competition, as one of his 'Personal Choice' songs, Shannon even covered one of Barnes' more well-known solo releases, 'Working-Class Man.’

The different assumptions of the judges and the audience, reflecting the much earlier difference between New Faces and Opportunity Knocks, is well brought-out in the judges' shock in Idol 1 at the exit of Paulini Curuenavuli and, in Idol 2, at the exit of Ricki-Lee Coulter when not enough of the audience voted for them. Two weeks before she was knocked out of the competition, Paulini got so few votes that she was placed in the bottom three for that week. When this was revealed, the judges were shocked. There was general agreement that Paulini had one of the best voices in Idol 1. Holden said: 'It's a disgrace,' and Hines said: 'I really hope Australians are voting for the contestant with the best voice. ${ }^{50}$ Paulini finally finished fourth. Likewise, in Idol 2, Ricki-Lee came seventh. In the Australian Made week, she sang 'Hopelessly Devoted To You,' the Olivia Newton-John song from Grease. Like Paulini, Ricki-Lee was generally regarded as having an exceptional voice. When she was knocked out many people blamed Dicko for criticising the way she looked. He told her: 'The message you're sending to me with the earrings and the shoes is like Las Vegas bling bling and the suit looks like you're power-dressing for a training seminar at an insurance company or something.' Dicko’s 
point was that Ricki-Lee wasn't appealing to the right audience, what he saw as the girls—as he said to another, male, contestant: 'You've got the chicks, definitely.' RickiLee appealed more to the older generation who were watching for entertainment and who, on the whole, most probably didn't vote. In both cases, though, it's clear that what was really the problem for the voting audience was that they had trouble identifying with Paulini and Ricki-Lee because of the quality of their voices. Ricki-Lee's dress sense just didn't help. Here we have two examples of the tension between what the judges and what the voting audience were looking for.

The formal claim of Australian Idol is that it seeks to find the best singer in the competition and it utilises a voting system that, it implies, enables ordinary people to bring this about. The assumption about ordinariness here is a kind of neo-Rousseauean sense of an expression of the General Will which, in this case, would lead to the 'best' singer becoming the winner. What actually happens, as we have seen, is that, while the judges attempt to find this best singer, the voting audience is more interested in somebody winning who is as 'ordinary' as they are (a common denominator, perhaps) or, at the least, who can offer the impression that, given the right circumstances, any ordinary person could win. Ordinary here, then, becomes a code word signalling the possibility of identification. The tension between the concerns of the judges and the audiences expresses a difference in the formats of Britain's two most well-known television talent shows, and the consequences of this. At the same time, the interactive voting system increasingly incorporates the audience into the spectacle of the show and thus into the capitalist fundamentals which underlie the show's organisation in, for example, the cost of voting. Where voters in Opportunity Knocks bought their own postcards and stamps, benefiting, in the main, the Royal Mail, Idol voters use dedicated lines which, as we have seen, produce revenue streams for both the Idol program and the telecommunications companies - in other words, to state the obvious, it is not only technology that has moved on since Opportunity Knocks, it is also the commercial efficiency of capitalist organisations. More generally, audiences have become more coopted, their interactive activity—-their apparent exercise of choice-actually producing them as part of what Debord described as the society of the spectacle. 
Su Holmes "Reality Goes Pop: Reality. TV, Popular Music, and Narratives of Stardom in Pop Idol', P.149.

Holmes “Reality Goes Pop,” P.149.

3 “Battle of the Brands,' Sydney Morning Herald, December 17 ${ }^{\text {th }}, 2002$.

$4 \quad$ Misha Kavka 'A Different Kind of Paradise: Reality Television in New Zealand' Metro Magazine, no 136, 2003,

This term comes from Geoffrey Stokes' book, Star-making Machinery: Inside the Business of Rock and Roll on the production and promotion of Commander Cody's 1975 album, Commander Cody and His Lost Planet Airmen.

In 'From Tit-Bits to Big Brother: a century of audience participation in the media,' Media, Culture \& Society, vol 226, no 4, 2004, pp 533-548, Bridget Griffen-Foley dispels the idea that audience participation and feedback is new in the media.

Toni Johnson-Woods Big Brother, P69.

Misha Kavka and Amy West 'Temporalities of the Real Conceptualising time in Reality TV, in Su Homes and Deborah Jermyn Eds. Understanding Reality Television, P.143.

Johnson-Woods Big Brother, P.1.

Johnson-Woods Big Brother, P.8.

Johnson-Woods Big Brother, P.22.

Greg Brooks ‘Endemol’ New Media Age, May 9' 2002.

Brooks 'Endemol'.

It is interesting to speculate on why Americans, it seems more than anybody else, are so interested in watching the televisual group vote each other out. In short, I would suggest that this is linked to the importance of competitive individualism in American culture.

Paul Sloan 'Factory: Fremantle Media didn’t invent reality TV...' Business 2.0, August 2004, Vol 5, no 7. 
Janine Stein 'In a world of Telco bells and whistles ...” Television Asia, JulyAugust, 2004

Suzanne Cabonne 'Your last chance to crate an Idol' The Age, 19 November 2004.

Paul Sexton 'It's already a global hit format ...' The Financial Times, 4 May 2004.

Sheila Whiteley Women and Popular Music, p. 225.

For a discussion of 'Wannabe' see Elizabeth Eva Leach 'Vicars of 'Wannabe': Authenticity and the Spice Girls' in Popular Music Vol 20, No 2, 200

Quoted in Whiteley Women and Popular Music, P. 219.

Quoted in Sloan 'Factory”

Daniel Boorstin The Image, P.11.

Guy Debond The Society of the Spectacle, P. 19.

“"Reality Goes Pop”, P. 149..

Debond The Society of the Spectacle, P. 12

Su Holmes 'All You've Got To Worry About Is the Task, Having a Cup of Tea, and Doing a Bit of Sunbathing: Approaching Celebrity in Big Brother' in Holmes and Jermyn Understanding Reality Television, P. 113.

Raymond Williams 'Culture is Ordinary' quoted from its reproduction in Ann Gray and Jim McGuigan eds. Studying Culture: An Introductory Revealer, Second edition, P.6.

Quoted in Michael Bracewell England is Mine: Pop Life in Albion from Wilde to Goldie, p. 62.

Estella Tincknell and Parvati Raghuram 'Big Brother: Reconfiguring the 'active' audience in cultural studies?' in Holmes and Jermyn Understanding Reality Television, P. 258.

Tincknell and Raghuram ‘Big Brother,’ P. 25B

Michel De Certeau The Practice of Everyday Life, Vol 2, P .

Kavka 'A Different Kind of Paradise'

Tincknell and Raghuram ‘Big Brother,’ P. 253.

Ien Ang Living Room Wars, P.10. 
Ang Living Room Wars, P.12. 